Jurnal Sistem Informasi (Journal of Information Systems). 2/12 (2016), 90-94

DOI: http://dx.doi.org/10.21609/jsi.v12i2.491

\title{
FAKTOR-FAKTOR YANG MEMENGARUHI KNOWLEDGE SHARING DI ANTARA DOSEN (STUDI KASUS STIKOM UYELINDO DAN STIKOM ARTHA BUANA)
}

\author{
Semlinda Juszandri Bulan \\ Program Studi Sistem Informasi, STIKOM Uyelindo Kupang, Jl. Perintis Kemerdekaan I, Kota Kupang, \\ 85228, Indonesia \\ E-mail: semlinda@yahoo.com
}

\begin{abstract}
Knowledge sharing in an organization is a very important thing, one of the impact of these activities is to improve the performance of the organization. In academic sector, effective knowledge sharing among lecturers can improve the performance of a university. The purpose of this research is to determine the factors that influencing lecturers in Kupang in conducting knowledge sharing. The number of samples in this research is 43 lecturers from two universities in Kupang. Data is analyzed using Partial Least Square with help of SmartPLS. The results show that Reward System and Information Technology Use positively influencing knowledge sharing among academic staffs and knowledge sharing positively affects the performance of the universities in Kupang, East Nusa Tenggara.
\end{abstract}

Keywords: knowledge sharing, individual factor, organization factor, tecnology factor, lecturer

\begin{abstract}
Abstrak
Knowledge sharing atau berbagi pengetahuan dalam suatu organisasi merupakan hal yang sangat penting, salah satu dampak dari knowledge sharing ini adalah dapat meningkatkan performance dari organisasi tersebut. Dalam dunia pendidikan, knowledge sharing yang efektif di antara dosen dapat meningkatkan performance dari suatu perguruan tinggi. Tujuan dari penelitian ini adalah untuk mengetahui faktor-faktor apa saja yang memengaruhi knowledge sharing di antara dosen di Kupang. Jumlah sampel dalam penelitian ini adalah 43 dosen dari dua perguruan tinggi yang berada di Kupang. Analisis data dilakukan dengan menggunakan metode Partial Least Square yang dijalankan dengan software SmartPLS. Hasil analisis menunjukkan bahwa Sistem Penghargaan dan Penggunaan Teknologi Informasi positif memengaruhi knowledge sharing di antara dosen di Kupang, Nusa Tenggara Timur.
\end{abstract}

Kata Kunci: knowledge sharing, faktor individu, faktor organisasi, faktor teknologi, dosen

\section{Pendahuluan}

Knowledge sharing (berbagi pengetahuan) dalam sebuah organisasi adalah hal yang sangat penting. Sejumlah penelitian telah menunjukkan bahwa knowledge sharing jelas merupakan proses penting karena memungkinkan organisasi untuk meningkatkan inovasi dan kinerja organisasi [1]. Oleh sebab itu, knowledge sharing penting untuk keberhasilan dan perkembangan suatu lembaga pendidikan.

Dalam organisasi yang berbasis pengetahuan seperti universitas atau perguruan tinggi, knowledge sharing adalah hal yang sangat penting karena sebagian besar karyawan adalah knowledge workers. Dalam dunia pendidikan, knowledge sharing yang efektif akan menyebabkan para akademisi dapat menyadari dan mengembangkan potensi mereka sepenuhnya.

Salah satu provinsi di Indonesia yang dikenal terbelakang dalam dunia pendidikan, salah sa- tunya adalah Nusa Tenggara Timur (NTT). Oleh karena itu, dalam penelitian ini akan dilakukan analisis untuk mengetahui faktor-faktor apa saja yang memengaruhi knowledge sharing di antara dosen di Kupang (studi kasus STIKOM Uyelindo dan STIKOM Artha Buana). Kedua perguruan tinggi ini dipilih karena kemudahan akses.

Dalam penelitian ini, data akan dianalisis menggunakan metode Partial Least Square yang dijalankan dengan perangkat lunak SmartPLS. Faktor-faktor yang memengaruhi knowledge sharing, dibagi ke dalam tiga ke kelompok yaitu faktor individu, faktor organisasi dan faktor teknologi [2]. Penelitian ini bertujuan untuk menguji faktorfaktor apa saja yang memengaruhi knowledge sharing di antara dosen di Kupang.

Faktor-faktor yang memengaruhi knowledge sharing, dibagi ke dalam tiga ke kelompok yaitu faktor individu, faktor organisasi dan faktor teknologi. 


\section{Faktor Individu}

Wasko dan Faraj dalam [3] menyatakan bahwa staf mengejar eksplorasi intelektual melalui tantangan dan kesenangan agar dapat memecahkan masalah dasar, mereka akan mengalami kesenangan dalam berbagi pengetahuan yang mereka miliki dengan orang lain untuk eksplorasi intelektual. Knowledge worker yang senang membantu orang lain akan lebih cenderung untuk mau berbagi pengetahuan [4].

Self efficacy didefinisikan sebagai "the judgments of individuals regarding their capabilities to organize and execute courses of action required to achieve specific levels of performance" (Bandura dalam [4]). Self efficacy menentukan kesediaan dari seseorang untuk melakukan kegiatan tertentu (Bandura dalam [5]). Penelitian oleh [5] berpendapat bahwa lingkungan individu berkontribusi terhadap formulasi self efficacy yang mengarah pada knowledge sharing.

Berdasarkan teori tersebut maka dikembangkan hipotesis sebagai berikut:

H1: Kesenangan berbagi berpengaruh terhadap knowledge sharing

$\mathrm{H} 2$ : Kemampuan berbagi berbagi berpengaruh terhadap knowledge sharing

\section{Faktor Organisasi (Organizational Factors)}

Dukungan manajemen dipertimbangkan sebagai satu pengaruh penting terhadap pengetahuan organisasi (Cornelly dan Kelloway dalam [4]). Banyak studi telah menemukan bahwa dukungan manajemen, penting untuk menciptakan iklim yang mendukung dan menyediakan sumber daya yang cukup [4].

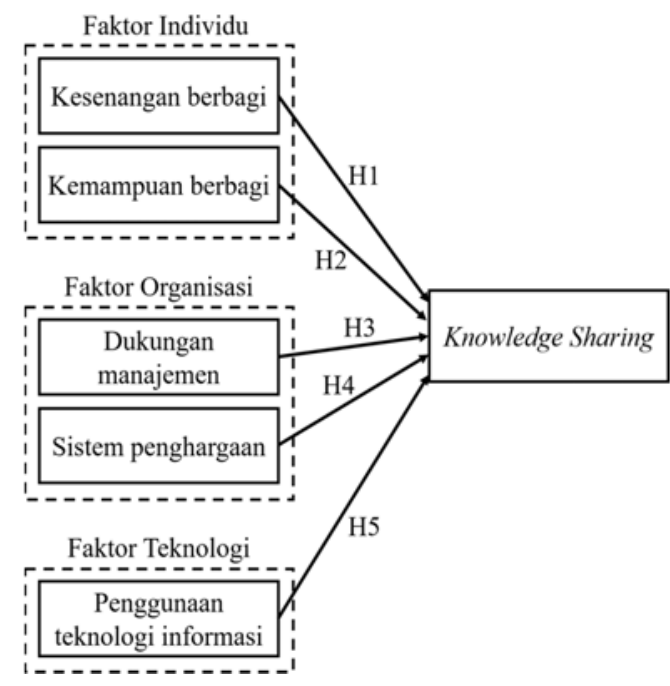

Gambar 1. Model knowledge sharing [3]
Menurut Cabrera dan Bonache dalam [4], organizational rewards mengindikasikan bentuk nilai dari organisasi atas behavior karyawan. Reward dapat bertingkat dari insentif monetary seperti peningkatan gaji dan bonus sampai ke penghargaan non-monetary seperti promosi dan keamanan kerja. Menurut [4], beberapa organisasi telah memperkenalkan sistem penghargaan untuk mendorong karyawan agar berbagi pengetahuan.

Berdasarkan teori tersebut maka dikembangkan hipotesis sebagai berikut:

H3: Dukungan manajemen berpengaruh terhadap knowledge sharing

H4: Sistem penghargaan berpengaruh terhadap knowledge sharing

\section{Faktor Teknologi (Technological Factors)}

Penggunaan information and communication technology (ICT) dan knowledge sharing sangat berhubungan, karena ICT memungkinkan pencarian secara cepat, akses dan pengambilan informasi dan dapat mendukung komunikasi dan kolaborasi diantara karyawan dalam organisasi (Huys-man dan Wulf dalam [5]). Di dalam knowledge sharing, penggunaan ICT memfasilitasi pengembangan metode baru dan aplikasi (seperti groupware, online databases, intranet, virtual communities dan lain-lain) dan memberikan perusahaan untuk mengembangkan jaringan sosial yang tersedia dengan mengatasi batasan geografi dan mendapatkan aktivitas kolaborasi yang efektif (Pan dan Leidner dalam [4]).

Berdasarkan teori tersebut maka dikembangkan hipotesis sebagai berikut:

H5: Penggunaan teknologi informasi berpengaruh terhadap knowledge sharing.

Berdasarkan landasan teori dan hipotesis yang ada, maka model model knowledge sharing di antara dosen dalam penelitian ini dapat dilihat pada Gambar 1.

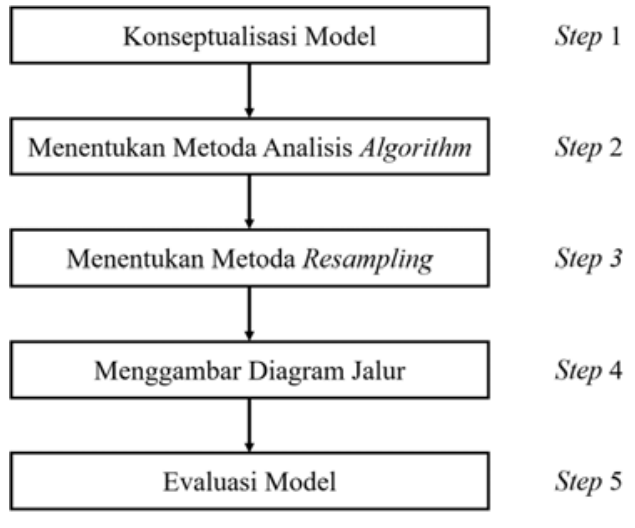

Gambar 2. Tahapan analisis menggunakan PLS-SEM 


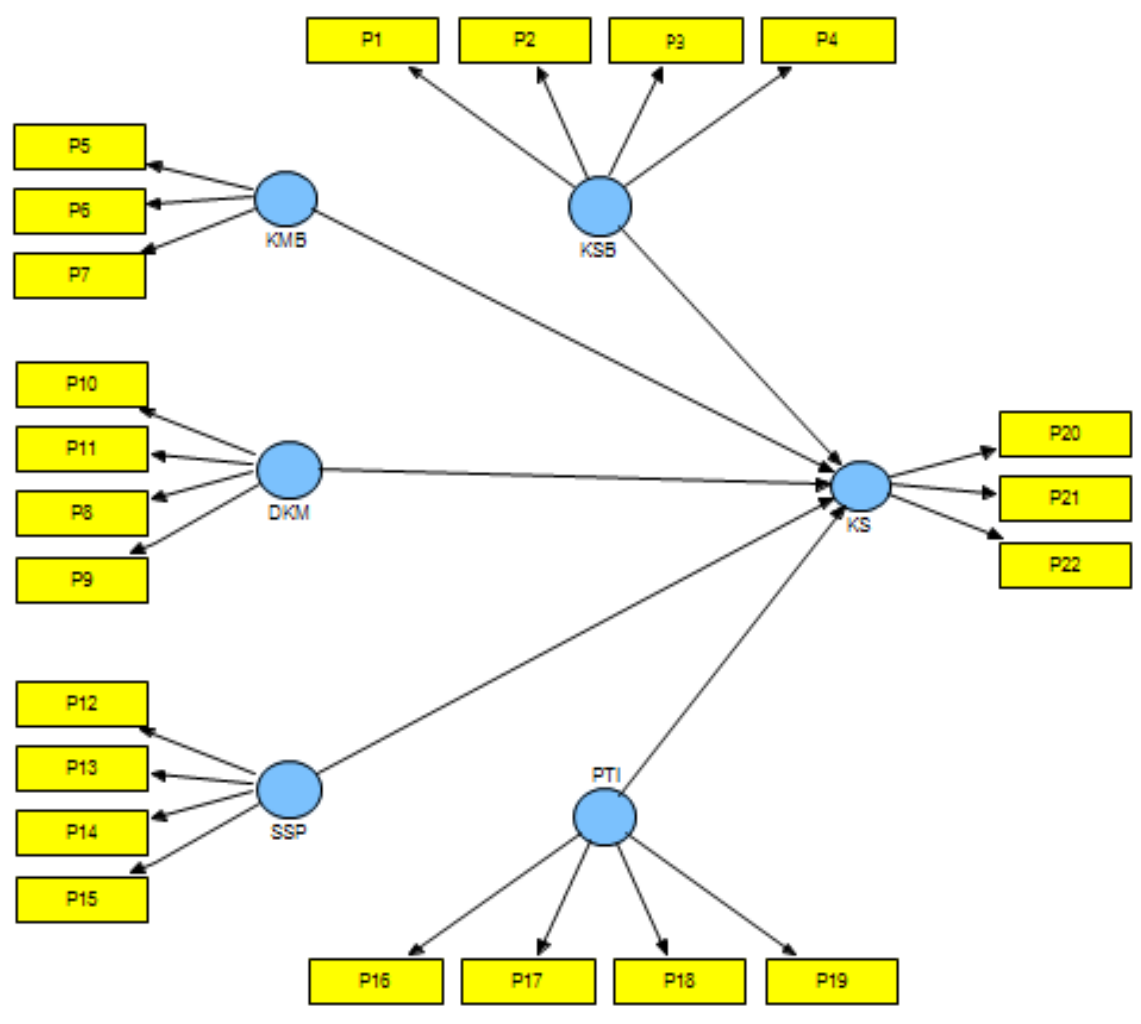

Gambar 3. Diagram Jalur

\section{Metode Penelitian}

Populasi dalam penelitian ini adalah dosen dari sekolah tinggi informatika yang berada di Kupang Nusa Tenggara Timur. Sampel dalam penelitian ini adalah dosen dari 2 sekolah tinggi informatika yang mewakili masing-masing program studi dari setiap jenjang yang ada. Penelitian ini dilakukan pada STIKOM Uyelindo dan STIKOM Artha Buana Kupang Nusa Tenggara Timur.

Pengumpulan data dalam penelitian ini dilakukan dengan menyebarkan kuesioner kepada dosen. Pernyataan kuesioner merupakan pernyataan yang tertutup yang terdiri dari 4 bagian yaitu Faktor Individu, Faktor Organisasi, dan Faktor Teknologi. Kuesioner terdiri dari 22 pernyataan dengan jawaban seberapa jauh responden setuju atau tidak setuju terhadap pernyataan-pernyataan yang diajukan dalam kuesioner. Pemberian skor dengan menggunakan skala Likert 5 poin.

Penelitian [6] menyatakan bahwa tahapan analisis menggunakan PLS-SEM (partial least squares-structural equation modeling) setidaknya harus melalui 5 proses tahapan yaitu: 1) Konseptualisasi model; 2) Menentukan metoda analisis algorithm; 3) Menentukan metoda resampling; 4) Menggambar diagram jalur; 5) Evaluasi model.
Pengolahan data dilakukan dengan metode Partial Least Square (PLS) dan menggunakan software SmartPLS 2.0 M3.

Pengujian hipotesis dilakukan dengan cara evaluasi model pengukuran (outer model) untuk mengevaluasi hubungan antara variabel konstruk dengan indikator. Evaluasi model pengukuran dilakukan dengan menilai validitas dan reliabilitas model. Outer model dengan indikator refleksif dievaluasi melalui convergent valididy dan discriminant validity dari indikator pembentuk konstruk laten dan composite realibility serta cronbach alpha untuk blok indikatornya.

Kemudian dengan evaluasi model struktural (inner model) digunakan untuk mengevaluasi hasil estimasi parameter path coefficiency dan tingkat signifikansinya. Evaluasi ini dilakukan dengan melihat nilai $\mathrm{R}^{2}$ dan nilai koefisen jalur atau $t-v a-$ lues tiap jalur untuk uji signifikansi antar variabel dalam model.

Dalam penelitian ini, variabel-variabel yang memengaruhi Knowledge Sharing dibagi menjadi tiga faktor yaitu faktor individu, ruang organisasi, dan teknologi. Faktor Individu (Individual Factors) diukur menggunakan dua parameter yaitu: Kesenangan berbagi (pleasure of sharing) dan Kemampuan berbagi (self efficacy). Faktor Organisasi (Organizational Factors) diukur menggu- 
TABEL 1.

PROFIL RESPONDEN

\begin{tabular}{lcc}
\hline Profil Responden & Jumlah & Persentase (\%) \\
\hline Jenis kelamin & & \\
Laki-laki & 26 & 60.47 \\
Perempuan & 17 & 39.53 \\
Umur (tahun) & & \\
$20-30$ & 18 & 41.86 \\
$31-40$ & 15 & 34.89 \\
$41-50$ & 9 & 20.93 \\
$>50$ & 1 & 2.32 \\
Status & & \\
Menikah & 26 & 60.47 \\
Belum menikah & 17 & 39.53 \\
Pendidikan & & \\
Master & 36 & 83,73 \\
Doktor & 0 & 0 \\
Tidak diisi & 7 & 16.27 \\
Pengalaman kerja (tahun) & & \\
1 - 5 & 21 & 48.84 \\
- 10 & 9 & 20.93 \\
11 - 20 & 11 & 25.59 \\
> 20 & 1 & 2.32 \\
Tidak diisi & 1 & 2.32 \\
Nama institusi & & \\
STIKOM Uyelindo & 32 & 74.41 \\
STIKOM Artha Buana & 11 & 25.59 \\
\hline
\end{tabular}

nakan dua parameter yaitu: Dukungan manajemen (management support) dan Sistem penghargaan (reward system). Faktor Teknologi (Technological Factors) diukur menggunakan satu parameter yaitu: penggunaan teknologi informasi (information technology use).

\section{Hasil dan Pembahasan}

Jumlah sampel pada penelitian ini sama dengan jumlah populasi yang ada. Responden yang terlibat dalam penelitian ini berjumlah 43 dosen dengan tingkat respon sebesar $86 \%$. Profil dari responden dapat dilihat pada Tabel 1.

Berdasarkan Tabel 1 terlihat bahwa sebagian besar responden adalah laki-laki $(60.47 \%)$ berumur antara 20-23 tahun (41.86\%), berstatus menikah $60.47 \%$, berpendidikan Master $83.73 \%$ dengan pengalaman kerja antara 1-5 tahun (48.84\%). Responden terbanyak berasal dari STIKOM Uyelindo (74.41\%).

Dalam penelitian ini pengujian hipotesis menggunakan metode Partial Least Square (PLS) dan software yang digunakan adalah SmartPLS 2.0 M3. Diagram jalur dari model dalam penelitian ini terlihat pada Gambar 3.

Pada Gambar 3 terdapat 6 kontruk beserta dengan indikator-indikatornya. Arah panah antara indikator dengan kontruk laten adalah menuju indikator yang menunjukkan bahwa penelitian menggunakan indikator reflektif. Hubungan yang akan diteliti (hipotesis) dilambangkan dengan anak panah antara konstruk. Penjelasan konstruk beserta dengan indikator-indikatornya dapat dilihat pa-
TABEL 2.

\begin{tabular}{|c|c|c|}
\hline \multicolumn{3}{|c|}{ KONSTRUK DAN INDIKATORNYA } \\
\hline No. & Nama Konstruk & $\begin{array}{l}\text { Nama } \\
\text { Indikator }\end{array}$ \\
\hline \multicolumn{3}{|c|}{ Faktor Individu } \\
\hline 1 & Kesenangan Berbagi (KSB) & P1, P2, P3, P4 \\
\hline 2 & Kemampuan Berbagi (KMB) & P5, P6, P7 \\
\hline \multicolumn{3}{|c|}{ Faktor Organisasi } \\
\hline 3 & Dukungan Manajemen (DKM) & $\begin{array}{l}\text { P8, P9, P10, } \\
\text { P11 }\end{array}$ \\
\hline 4 & Sistem Penghargaan (SSP) & $\begin{array}{l}\text { P12, P13, P14, } \\
\text { P15 }\end{array}$ \\
\hline \multicolumn{3}{|c|}{ Faktor Teknologi } \\
\hline 5 & $\begin{array}{l}\text { Penggunaan Teknologi Informasi } \\
\text { (PTI) }\end{array}$ & $\begin{array}{l}\text { P16, P17, P18, } \\
\text { P19 }\end{array}$ \\
\hline 6 & Knowledge Sharing (KS) & P20, P21, P22 \\
\hline
\end{tabular}

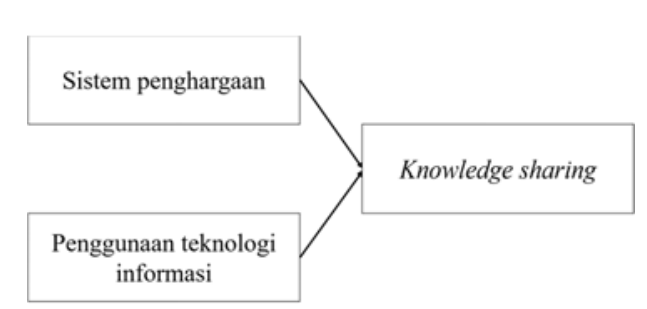

Gambar 4. Model knowledge sharing di antara dosen di Kupang

\section{da Tabel 2.}

Hasil evaluasi model pengukuran konstruk refleksif untuk model penelitian ini, dapat dilihat pada Tabel 3. Semua konstruk memiliki nilai AVE dan Communality di atas 0.5 , hal ini menunjukkan bahwa konstruk memiliki Validitas Convergent yang baik. Nilai Composite Reliability yang dihasilkan oleh semua konstruk sangat baik yaitu di atas 0.7 sehingga dapat disimpulkan bahwa semua indikator konstruk adalah reliabel atau memenuhi uji reliabilitas. Nilai akar kuadrat AVE suatu konstruk lebih tinggi dari korelasinya dengan konstruk lainnya, maka dikatakan validitas discrimantnya baik

Setelah pemeriksaan convergent validity dan discriminant validity terpenuhi, selanjutnya adalah evaluasi model struktural. Path Coefficients dapat dilihat pada Tabel 4 (terlampir). Berdasarkan data pada Tabel 4 maka hubungan jalur yang signifikan/diterima (*) adalah PTI (Penggunaan Teknologi Informasi) terhadap KS (hipotesis 5) dan SSP (Sistem Penghargaan) terhadap KS (hipotesis 4) karena memiliki nilai T Statistics lebih besar dari 1.96 yaitu 3.14 dan 2.99 .

Berdasarkan hasil penelitian yang telah dilakukan, maka model knowledge sharing antara dosen di Kupang (studi kasus STIKOM Uyelindo dan STIKOM Artha Buana) dapat dilihat pada Gambar 4. 
TABEL 3.

OVERVIEW EVALUASI MODEL PENGUKURAN

\begin{tabular}{llllll}
\multicolumn{6}{c}{ OVERVIEW EVALUASI MODEL PENGUKURAN } \\
\hline \multirow{2}{*}{ Konstruk } & AVE & $\begin{array}{l}\text { Composite } \\
\text { Reliability }\end{array}$ & $\begin{array}{l}\text { Cronbachs } \\
\text { Alpha }\end{array}$ & Communality & Redundancy \\
\hline DKM & 1,000000 & 1,000000 & 1,000000 & 1,000000 & \\
KMB & 1,000000 & 1,000000 & 1,000000 & 1,000000 & \\
KS & 0,820195 & 0,901143 & 0,784446 & 0,820196 & $-0,128259$ \\
KSB & 0,730487 & 0,915340 & 0,877528 & 0,730487 & \\
PTI & 0,713147 & 0,908390 & 0,877079 & 0,713147 & \\
SSP & 0,827283 & 0,905343 & 0,798802 & 0,827283 & \\
DKM & 1,000000 & 1,000000 & 1,000000 & 1,000000 & \\
\hline
\end{tabular}

TABEL 4.

Path CoEfFicients (Mean, STDEV, T-Values)

\begin{tabular}{llllll}
\hline Konstruk & $\begin{array}{l}\text { Original } \\
\text { Sample }(\mathrm{O})\end{array}$ & $\begin{array}{l}\text { Sample Mean } \\
(\mathrm{M})\end{array}$ & $\begin{array}{l}\text { Standard Deviation } \\
(\mathrm{STDEV})\end{array}$ & $\begin{array}{l}\text { Standard Error } \\
(\mathrm{STERR})\end{array}$ & $\begin{array}{l}\text { T Statistics } \\
(\mid \mathrm{O} / \mathrm{STERR})\end{array}$ \\
\hline DKM-> KS & $-0,255605$ & $-0,258599$ & 0,139348 & 0,139348 & 1,834297 \\
KMB -> KS & 0,068030 & 0,054781 & 0,112653 & 0,112653 & 0,603890 \\
KSB -> KS & 0,169459 & 0,181460 & 0,111218 & 0,111218 & 1,523666 \\
PTI -> KS & 0,431701 & 0,438285 & 0,137187 & 0,137187 & $3,146814^{*}$ \\
SSP -> KS & 0,191385 & 0,200218 & 0,063944 & 0,063944 & $2,993001^{*}$ \\
\hline K
\end{tabular}

Keterangan:

KMB (Kemampuan Berbagi), KSB (Kesenangan Berbagi), PTI (Penggunaan Teknologi Informasi), SSP (Sistem Penghargaan), DKM (Dukungan Manajemen), KS (Knowledge Sharing).

Dari Gambar 4 terlihat bahwa faktor-faktor yang memengaruhi knowledge sharing di antara dosen di Kupang yaitu Sistem Penghargaan dan Penggunaan Teknologi Informasi. Semakin besar Sistem Penghargaan dan Penggunaan Teknologi Informasi, maka akan semakin meningkatkan knowledge sharing di antara dosen. Jika perguruan tinggi ingin meningkatkan knowledge sharing di antara dosen maka faktor-faktor yang sangat penting untuk diperhatikan adalah Sistem Penghargaan dan Penggunaan Teknologi Informasi.

\section{Kesimpulan}

Dalam penelitian ini, dilakukan analisis untuk mengetahui faktor-faktor apa saja yang memengaruhi knowledge sharing di antara dosen di Kupang. Berdasarkan analisis yang telah dilakukan, diperoleh kesimpulan bahwa faktor yang memengaruhi knowledge sharing di antara dosen di Kupang adalah Sistem Penghargaan dan Penggunaan Tekn-logi Informasi. Semakin besar Sistem Penghargaan dan Penggunaan Teknologi Informasi pada masing-masing perguruan tinggi, maka akan semakin meningkatkan knowledge sharing di antara dosen.

Untuk penelitian selanjutnya, perlu dilakukan penambahan responden dan peneliti dapat mempertimbangkan faktor-faktor lain yang belum dimasukkan sebagai hipotesis dalam penelitian ini sebagai faktor-faktor yang memengaruhi knowledge sharing di antara dosen.

\section{Referensi}

[1] Becerra-Fernandez, I., dan Sabherwal, R., Knowledge Management: Systems and Processes, M.E. Sharpe, New York, 2010.

[2] Riege, Andreas, "Three-dozen KnowledgeSharing Barriers Managers Must Consider", Journal of Knowledge Management, pp. 1835, 2005.

[3] Lee, J., Kim, J., dan Han, Y., "A Study on Factors Influencing Knowledge-Sharing Activity for the Innovation Activity of Team", IEEE, pp. 270-274, 2010.

[4] Lin, H.F., "Knowledge Sharing and Firm Innovation Capability: an Empirical Study, International Journal of Manpower, Emerald Group Publishing Limited”, pp. 315-332, 2007.

[5] Kwakye, E.O. dan Nor, K.Md., "Individual Factors and Knowledge Sharing", American Journal of Economics and Business Administration, pp. 66-72, 2011.

[5] Endres, M.L., S.P. Endres, S.K. Chowdhury dan I. Alam, "Tacit Knowledge Sharing, Theory and Application to The Open Community", Journal Knowledge Management, pp. 92-100, 2007.

[6] Latan, Hengky dan Ghozali Imam, Partial Least Square Konsep, Teknik dan Aplikasi SmartPLS 2.0 M3, Badan Penerbit Universitas Diponegoro, Semarang, 2012. 